\title{
Profiling of microRNAs in actinic keratosis and cutaneous squamous cell carcinoma patients
}

\author{
Aleksandra Dańczak-Pazdrowska ${ }^{1} \cdot$ Jakub Pazdrowski ${ }^{2,3} \cdot$ Adriana Polańska $^{4}\left(10 \cdot\right.$ Brittany Basta $^{7,8}$. \\ Augusto Schneider ${ }^{9} \cdot$ Michał J. Kowalczyk $^{4} \cdot$ Paweł Golusiński ${ }^{5,6} \cdot$ Wojciech Golusiński ${ }^{2,3} \cdot$ Zygmunt Adamski $^{1}$. \\ Ryszard Żaba ${ }^{4}$ Michal M. Masternak ${ }^{7}$
}

Received: 12 October 2020 / Revised: 16 February 2021 / Accepted: 18 March 2021 / Published online: 4 April 2021

(c) The Author(s) 2021

\begin{abstract}
Actinic keratosis (AK) is a common skin lesion often defined as premalignant with more evidence indicating it as early stage of cutaneous squamous cell carcinoma ( $\mathrm{CSCC}$ ). The AK may remain stable, transform towards incisive cSCC or in some cases revert spontaneously. Several different underlying conditions can increase risk of cSCC, however, advanced age represents major risk of $\mathrm{AK}$ and its progression towards $\mathrm{cSCC}$ indicating increased risk during chronological aging. Importantly, AK and cSCC are characterized by similar genetic profile, which lead researchers to search for novel biomarkers allowing early detection. As skin sampling is often invasive and causes scaring, in the current study, we investigated a novel approach to establish potential blood circulating genetic markers in patients diagnosed with AK and cSCC. Based on clinical diagnosis and dermoscopy, we recruited 13 patients with AK (divided into two groups: the first included patients with no more than three lesions, the second group included patients with at least ten lesions) and two additional individuals diagnosed with cSCC. Deep sequencing analysis of serum circulating miRNAs detected a total of 68 expressed miRNAs. Further analysis indicated 2 regulated miRNAs for AK cohort and 12 miRNAs for cSCC patients, while there were 26 miRNAs differentially regulated between cSCC and AK patients. There was also one commonly regulated miRNA between AK and cSCC patients and ten miRNAs that were regulated in $\mathrm{CSCC}$ when compared with both control and AK patients. We did not observe any differences between the AK groups. In conclusion, our analysis detected in circulation some miRNA that were previously recognized as important in $\mathrm{AK}, \mathrm{cSCC}$, and other type of skin cancer supporting this approach as potential non-invasive diagnosis of $\mathrm{AK}$ and $\mathrm{CSCC}$.
\end{abstract}

Keywords AK $\cdot$ CSCC $\cdot$ MiRNA $\cdot$ Cancer $\cdot$ Epigenetics

\section{Introduction}

Aleksandra Dańczak-Pazdrowska and Jakub Pazdrowski are both the first authors and they were equally involved in writing the work.

Adriana Polańska

adriana-polanska@wp.pl

1 Department of Dermatology, Poznan University of Medical Sciences, Poznan, Poland

2 Department of Head and Neck Surgery, Poznan University of Medical Sciences, Poznan, Poland

3 Department of Head and Neck Surgery, The Greater Poland Cancer Centre, Poznan, Poland

4 Department of Dermatology and Venereology, Poznan University of Medical Sciences, Poznan, Poland
Actinic keratosis (AK) previously defined as a premalignant lesion, by many experts, is currently recognized as the early stage of cutaneous squamous cell carcinoma (cSCC). Both

5 Department of Otolaryngolgy and Maxillofacial Surgery, University of Zielona Góra, Zielona Góra, Poland

6 Department of Maxillofacial Surgey, Poznan University of Medical Sciences, Poznan, Poland

7 College of Medicine, Burnett School of Biomedical Sciences, University of Central Florida, Orlando, FL, USA

8 Barbara Davis Center for Diabetes, , University of Colorado School of Medicine, Aurora, CO, USA

9 Faculdade de Nutrição, Universidade Federal de Pelotas, Pelotas, RS, Brazil 
$\mathrm{AK}$ and $\mathrm{cSCC}$ share some similarities in genetic profile and histopathological features [1-4]. Importantly, NMSC represents one of the most common types of cancer, especially among Caucasians, with 1 million new cases per year in the United States, and cSSC also represents the second most common skin malignancy (20\% of all nonmelanoma skin cancers, NMSCs), although most of statistical data seem to be underestimated [5, 6]. All NMSCs are associated with a substantial morbidity but in contrast to basal cell carcinoma, cSCC is characterized by much higher risk of metastases $[5,6]$. The vast majority of cSSC arise from AK, and the prevalence of AK was estimated at 11-25\% with significant increase during chronological age [1, 2, 4]. All those observations indicate $\mathrm{AK}$ as one of the most common dermatological condition and a very important health care concern especially for growing elderly populations.

By analogy with histopathological classification of other intraepithelial neoplasia, AK is classified into three stages: keratinocytic intraepidermal neoplasma (KIN) I-III, in which KIN I represents the mildest stage of AK with atypical keratinocytes located only in the lower third of epidermis, while KIN III describes involvement of full epidermis thickness. Importantly, AK occurs mainly on a sun damaged skin of head and neck called field cancerization. In this particular area, disseminated atypical basal keratinocytes can be observed despite the lack of clinically obvious AK [1, 2, 4]. Given that cSCC can appear within clinically silent area or KIN I, so called "differentiated pathway" of transformation which is believed to be more common and more aggressive than progression from KIN III, and on the other hand some AK lesions may undergo spontaneous clinical regression, currently it cannot be anticipated which AK would eventually transform into cSCC based on clinicopathological findings [2,7]. Recent studies suggest that the genes EIF4EBPI, $S N X 17, P R P F 4, N X T 1$, and UBA5 can contribute to progression of AK into cSCC [8]. However, it is argued that the estimated annual risk of progression from AK to cSCC for an individual lesion is rather low, with assessed risk around $16 \%$, yet the cumulative risk for patients with multiple lesions is much more significant reaching up to $80 \%$, and the relative risk of transformation increases for those with more than five lesions [1-4]. Therefore, collectively data indicate that the multiple AK lesions might constitute one of the most important risk factor of progression to cSCC.

MicroRNAs (miRNAs) have an emerging role in the understanding of cancer pathophysiology and diagnosis. miRNAs comprise short ( $22 \mathrm{nt})$ single strand RNA molecules which are able to promote target mRNA cleavage and translation repression [9]. Understanding the regulation of oncogenes and tumor-suppressor genes is pivotal for diagnosis and treatment of cancer. In this context, it has been demonstrated that miRNAs can regulate cancer related genes [10]. miRNA profiling has proven effective in distinguishing several types of cancer, including breast cancer, glioblastoma, colorectal cancer, lung, and hepatocellular carcinoma [10]. Therefore, some miRNAs have been classified as oncogenic and tumor suppressor as well. One study identified that at least three different miRNAs were commonly regulated in breast, colon, lung, pancreas, prostate, and stomach cancers [11]. This evidence suggests miRNAs as involved in the development and progression of cancer. Our group has also shown before a miRNA signature in head and neck and colorectal cancer samples [12-14]. In cSCC, some miRNAs differentially regulated include miR-21, miR-205, miR-365, miR-34a, and miR-125b [15]. Additionally, miR-193b and miR-199b have a gradual regulation throughout the malignant evolution of AK to CSCC, while miR-19 and miR-126 seems early stage specific markers of AK [16]. Therefore, better understanding of specific miRNAs regulated during the evolution of AK to $\mathrm{CSCC}$ is required and will also provide confirmation of the role of miRNAs in this context.

However, miRNAs do not have an exclusively intracellular role and are found outside the cell, including in serum [17-19]. miRNAs can reach the extracellular environment through passive leakage from damaged cells or active secretion in exosomes [20]. In this sense, miRNAs in serum can target oncogenes/tumor-suppressor genes in distant or adjacent target cells [20]. Additionally, the pattern of serum miRNAs can be used as tool for non-invasive diagnosis [17, $21,22]$. Although some papers describing serum miRNAs in melanoma patients can be found [23], no literature for serum miRNAs in AK and cSCC can be found. In this context, the goal of our research was to assess if there is any difference in the expression of circulating miRNA within two groups of patients with AK: first one presented with no more than three lesions of $\mathrm{AK}$, and the second with at least ten lesions.

\section{Materials and methods}

\section{Patient selection}

Overall, 13 patients with AK within the skin of the head were recruited into this observational study based on clinical diagnosis and dermoscopy. The assessments were performed independently by two experienced dermatologist: ADP and AP. Including criteria for AK patients were: (a) Patient with 1-3 lesions or patients with at least 10 lesions; and (b) Otherwise healthy. Excluding criteria for AK patients were: (a) Patient with comorbidities; (b) Patients with more than 3 and less than 10 lesions; (c) Patients with clinical features that can suggest transformation to cSCC (induration, prominent inflammation, size $>1 \mathrm{~cm}$ in diameter, rapid growth, bleeding, and ulceration); d) Patients with previous NMSC. Patients were divided into two groups: the first group included patients with no more 
than three lesions of AK (6 patients, 4 men and 2women, mean age 73.2 years), the second group included patients with at least ten lesions of AK ( 7 patients, 6 men and 1 woman, mean age 84.3 years). The diagnosis of AK has not been confirmed by histopathological examination, but it is consistent with the recommendations of the International League of Dermatological Societies [24].

Additionally, two male patients with cSCC within the skin of head, otherwise health, were recruited to the study (mean age 73.5 years) and four healthy subjects ( 3 men and 1 woman, mean age 72,2 year). The diagnosis of cSCC was based on histopathological examination. Excluding criteria for cSCC patients: (i) Patient with comorbidities; (ii) Patients with the history or diagnosis during the recruitment with other cutaneous/noncutaneous neoplasm. Excluding criteria for healthy subjects: (a) comorbidities; (b) diagnosis of past or present oncological diseases. All patients included in the study were Caucasians with skin type II according to the Fitzpatrick classification. From all selected participant $5 \mathrm{ml}$ of whole blood sample was collected. Following centrifugation, serum samples were stored at $-80^{\circ} \mathrm{C}$.

The study was approved by a local bioethical committee (Poznan University of Medical Sciences, no 589/19). All patients gave written consent.

\section{RNA extraction and miRNA library preparation}

The samples were removed from the $-80^{\circ} \mathrm{C}$ freezer and homogenized with Qiazol (Qiagen, Valencia, CA, USA) using $0.5 \mathrm{~mm}$ zirconium oxide beads in the Bullet Blender 24 (Next Advance, Averill Park, NY, USA). Total RNA was extracted using a commercial column purification system (miRNeasy Mini Kit, Qiagen) and on-column DNase treatment (RNase-free DNase Set, Qiagen) following manufacturer's instructions.

MicroRNA libraries were prepared using the NEBNEXT Small RNA Library Prep Set for Illumina (New England Biolabs) following the manufacturer's instructions and adjusted by Matkovich, et al. [25]. Briefly, small RNAs from $1 \mu \mathrm{g}$ of total RNA were ligated with $3^{\prime}$ and $5^{\prime}$ adapters, followed by reverse transcription to produce single-stranded cDNAs. Samples were then amplified by PCR in 14 cycles using indexes to allow all individual libraries to be processed in a single flow cell lane during sequencing. The amplified libraries were size-selected and purified in a $6 \%$ agarose gel.

The quantity and quality of miRNA libraries were determined using BioAnalyzer and RNA Nano Lab Chip Kit (Agilent Technologies, Santa Clara, CA, USA), and the samples were combined in a single microtube and submitted to sequencing on a HiSeq 2500 instrument (Illumina Inc.).

\section{miRNAs libraries analysis and statistical analyses}

Alignment and quantification of miRNA libraries was performed using sRNAtoolbox as described before [26]. Statistical analyses of differentially expressed miRNAs were performed using EdgeR [27] on the R software (3.2.2) and miRNAs with a FDR $<0.05$ and $\mathrm{FC}>2.0$ were considered as up-regulated; and FDR $<0.05$ and $\mathrm{FC}<0.50$ were considered as down-regulated.

\section{miRNAs target prediction and enriched pathways and $\mathbf{G O}$ terms}

The mirPath tool (version 3.0) was used to predict target genes of the differentially regulated miRNAs using the microT-CDS v. 5.0 database [28] and for retrieving KEGG molecular pathways $[29,30]$, considering $P$ values lower than 0.05 as significant for pathway enrichment.

\section{Results}

After sequencing and processing of the RNASeq data, from an average of 9,650,146.05 $\pm 814,659.28$ raw reads, $5,503,515.68 \pm 337,285.95$ adapter cleaned reads/sample were obtained with $89 \%$ alignment rate to the human genome (hg19). A total of 68 different known miRNAs were identified in the serum of patients. PCA analysis and unsupervised hierarchical clustering of the samples indicate some distinction among groups (Fig. 1).

Based on the significant overlap among AK groups and the absence of differentially expressed miRNAs, we combined both AK groups in a single AK group. When comparing expression profile of AK patients, we observed 2 regulated miRNAs (Table 1), 12 miRNAs for cSCC patients (Table 1), and 26 miRNAs between cSCC and AK patients (Table 1). There was 1 commonly regulated miRNA between AK and cSCC patients and 10 miRNAs that were regulated in cSCC compared to both control and AK patients (Fig. 2).

Among the regulated pathways by target genes of these miRNAs, we observed that TGF-beta signaling pathway, cAMP signaling pathway, and signaling pathways regulating pluripotency of stem cells were commonly regulated in AK and cSCC samples (Table 2 and Fig. 3). Among the top regulated pathways, we also observed signaling pathways regulating pluripotency of stem cells, pathways in cancer and proteoglycans in cancer, further confirming the role of the miRNAs in the regulation of cancer pathophysiology (Tables 3 and 4). 

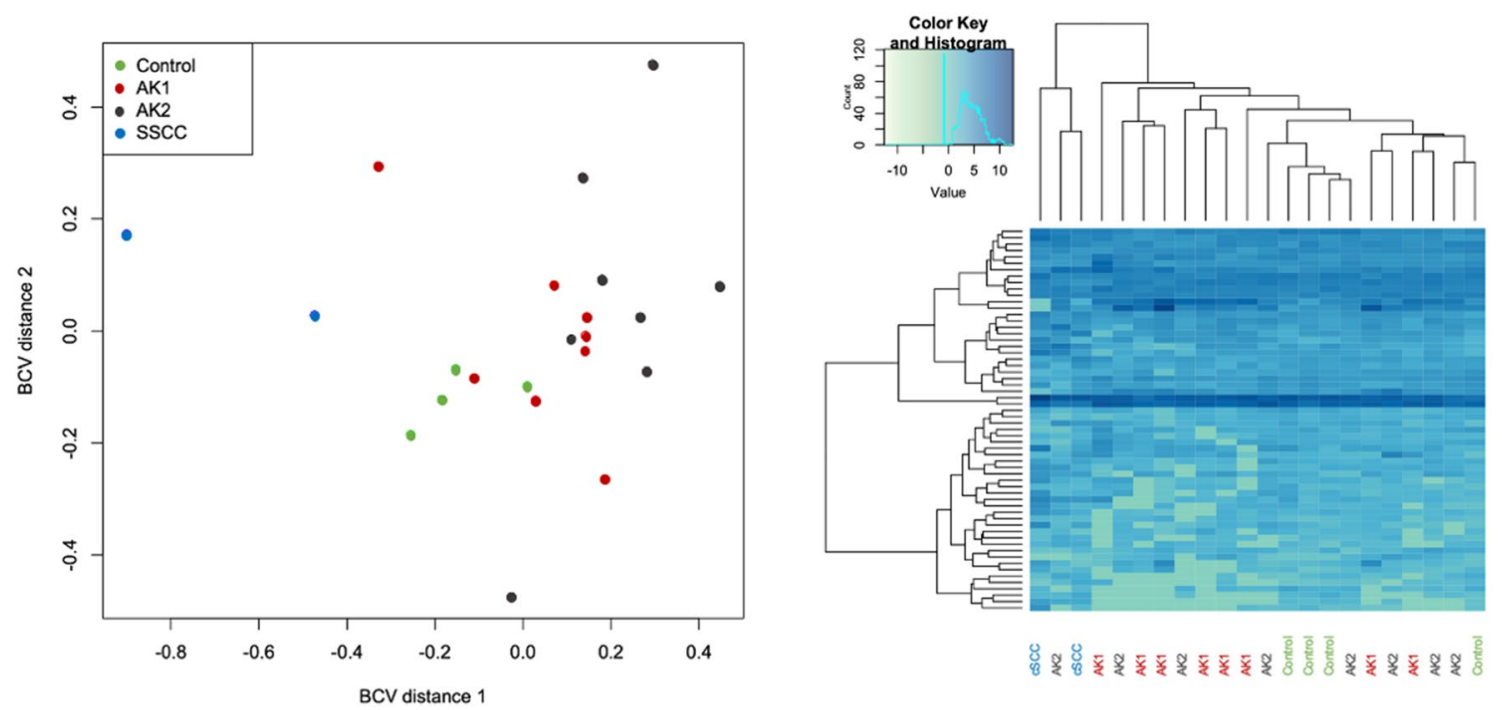

Fig. 1 a Principal component analysis and $\mathbf{b}$ unsupervised hierarchical clustering of the 60 miRNAs in skin samples from patients diagnosed with cancer

\section{Discussion}

The results of our current study indicate that several serum miRNAs were regulated in cSCC patients, although only two miRNAs were regulated in AK patients. This is expected as cSCC is a more progressed lesion and more miRNAs were, therefore, regulated. Additionally, our study indicates that there is no differential expressed serum miRNAs between patients with less than 3 or more than $10 \mathrm{AK}$ lesions. Interestingly, we observed that hsa-miR-101-3p was up-regulated in both $\mathrm{AK}$ and cSCC lesions, suggesting a common marker between these cells. Conversely, hsa-miR-3168 was upregulated in AK patients, while strongly down-regulated in cSCC lesions. When comparing our regulated serum miRNAs with a review on the subject we found that hsa- 142 and hsa-miR-186 were previously shown to be up-regulated in cSCC tissue samples [31]. Interestingly, hsa-miR-142 was the serum miRNA with the highest fold change in our study. Additionally a previous study has shown that hsa-miR-15b, hsa-let-7i, hsa-miR-140, hsa-miR-101, hsa-miR-16, hsamiR-22, and hsa-miR-107 were regulated in AK and cSCC tissue samples [16] and we also observed these miRNAs as being regulated in the serum of our patients. Therefore, providing further evidence that a signature of serum miRNAs can be observed in AK and cSCC patients.

miR-142 was 300 times up-regulated in cSCC serum samples. A previous study has shown that miR-142 is upregulated in cSCC tissue [32] and we previously found that miR-142-3p was up-regulated in tissue samples of head and neck cancer patients [13]. Others observed miR-142-3 as regulated in serum also [33], including as a serum marker of lung cancer recurrence [34]. miR-142 induced cancer stem cells like properties by targeting PTEN [32]. Loss of PTEN function is associated to cancer development [35]. In mice, conditional knockout of PTEN in skin leads to the development of neoplastic lesions [36]. In agreement with these evidences, we observed that signaling pathways regulating pluripotency of stem cells was the top regulated pathway by cSCC miRNA and also regulated by AK miRNAs, further confirming the role of miR-142 in this process. Cancer stem cells (CSCs) have the ability to differentiate in heterogeneous tumor cells, contributing for tumor initiation, growth, and recurrence [37]. Others have shown that the beta-catenin signaling pathway is essential to maintain stem cell-like phenotype in skin cancer [38]. Down-regulation of $\beta$-catenin by the proteoglycan decorin, blocks cell scatter, evasion and migration in cancer [39]. Thus, in agreement with our finding that the pathways proteoglycans in cancer was the second most regulated pathway in cSCC lesions.

We observed that miR-15b was up-regulated in serum of cSCC compared to AK patients. Previously miR-15b was observed as up-regulated in melanoma patients [40], suggesting a role for this miRNA in skin cancer. In melanoma tissue samples miR-15b was also observed to be up-regulated [41]. We also observed up-regulation of miR-101-3p in the serum of AK and cSCC patients. Previous studies with cSCC showed that miR-101 was down-regulated in cancer tissue [16]. The same is also observed in breast cancer, in which miR-101 inhibits the growth and proliferation of cancer cells [42]. miR-101-3p targets genes such as VEGF, mTOR, and involved in the focal adhesion, Wnt, and chemokine signaling pathways [43]. In serum, others have also found miR-101 to be down-regulated in cancer patients 
Table 1 -MicroRNAs differentially expressed in the serum of AK, SSCC, and healthy control patients

\begin{tabular}{|c|c|c|c|c|c|}
\hline $\operatorname{miRNA}^{\mathrm{a}}$ & Control & $\mathrm{AK}$ & $\mathrm{FC}^{\mathrm{b}}$ & $P$ value & $\mathrm{FDR}^{\mathrm{c}}$ \\
\hline hsa-miR-3168 & $56.97 \pm 13.64$ & $328.18 \pm 67.67$ & 5.74 & 0.0003 & 0.020 \\
\hline \multirow[t]{2}{*}{ hsa-miR-101-3p } & $8.55 \pm 1.19$ & $24.18 \pm 2.27$ & 2.75 & 0.0013 & 0.046 \\
\hline & Control & SSCC & $\mathrm{FC}$ & $P$ value & FDR \\
\hline hsa-miR-144-3p & $6.13 \pm 2.32$ & $98.46 \pm 79.96$ & 15.53 & 0.0002 & 0.021 \\
\hline hsa-miR-140-3p & $33.25 \pm 13.48$ & $246.74 \pm 97.35$ & 7.33 & 0.0004 & 0.025 \\
\hline hsa-let-7 g-5p & $66.01 \pm 14.93$ & $427.39 \pm 337.91$ & 6.46 & 0.0012 & 0.025 \\
\hline hsa-let-7i-5p & $170.85 \pm 26.99$ & $943.27 \pm 653.10$ & 5.52 & 0.0008 & 0.025 \\
\hline hsa-miR-103a-3p & $19.70 \pm 6.89$ & $154.39 \pm 78.40$ & 7.74 & 0.0007 & 0.025 \\
\hline hsa-miR-185-5p & $54.67 \pm 25.15$ & $428.64 \pm 353.85$ & 7.80 & 0.0013 & 0.025 \\
\hline hsa-miR-93-5p & $10.08 \pm 1.86$ & $83.64 \pm 70.04$ & 8.35 & 0.0014 & 0.025 \\
\hline hsa-miR-101-3p & $28.20 \pm 3.93$ & $190.05 \pm 172.78$ & 6.75 & 0.0030 & 0.035 \\
\hline hsa-miR-142-3p & $0.00 \pm 0.00$ & $10.53 \pm 7.96$ & 337.17 & 0.0029 & 0.035 \\
\hline hsa-miR-144-5p & $0.71 \pm 0.58$ & $19.87 \pm 16.08$ & 22.52 & 0.0024 & 0.035 \\
\hline hsa-miR-186-5p & $9.74 \pm 3.77$ & $89.14 \pm 75.54$ & 8.92 & 0.0030 & 0.035 \\
\hline \multirow[t]{2}{*}{ hsa-miR-3168 } & $184.41 \pm 44.06$ & $16.09 \pm 15.53$ & 0.08 & 0.0044 & 0.047 \\
\hline & $\mathrm{AK}$ & SSCC & $\mathrm{FC}$ & $P$ value & FDR \\
\hline hsa-miR-93-5p & $0.75 \pm 0.29$ & $26.82 \pm 23.40$ & 31.66 & $2.15 \mathrm{E}-07$ & $2.64 \mathrm{E}-05$ \\
\hline hsa-miR-185-5p & $18.04 \pm 2.40$ & $137.38 \pm 117.11$ & 7.63 & $2.83 \mathrm{E}-06$ & $1.74 \mathrm{E}-04$ \\
\hline hsa-miR-3168 & $407.19 \pm 82.16$ & $4.58 \pm 4.58$ & 0.01 & $4.63 \mathrm{E}-06$ & $1.90 \mathrm{E}-04$ \\
\hline hsa-miR-451a & $1065.99 \pm 103.22$ & $4445.68 \pm 2785.16$ & 4.17 & $9.03 \mathrm{E}-06$ & $2.78 \mathrm{E}-04$ \\
\hline hsa-miR-103a-3p & $5.1 \pm 1.18$ & $48.23 \pm 27.58$ & 9.09 & $2.87 \mathrm{E}-05$ & 0.001 \\
\hline hsa-miR-652-3p & $0.57 \pm 0.24$ & $11.94 \pm 9.86$ & 17.50 & $3.86 \mathrm{E}-05$ & 0.001 \\
\hline hsa-miR-107 & $1.55 \pm 0.35$ & $13.00 \pm 7.18$ & 7.96 & 0.0001 & 0.001 \\
\hline hsa-let-7i-5p & $71.41 \pm 10.14$ & $299.23 \pm 219.59$ & 4.17 & 0.0001 & 0.001 \\
\hline hsa-miR-144-3p & $2.81 \pm 0.68$ & $31.50 \pm 26.74$ & 11.15 & 0.0001 & 0.001 \\
\hline hsa-miR-17-5p & $0.17 \pm 0.16$ & $10.93 \pm 10.52$ & 54.10 & 0.0001 & 0.001 \\
\hline hsa-let-7 g-5p & $24.03 \pm 7.39$ & $136.60 \pm 112.29$ & 5.63 & 0.0006 & 0.006 \\
\hline hsa-miR-140-3p & $11.91 \pm 3.48$ & $76.42 \pm 35.50$ & 6.35 & 0.0009 & 0.008 \\
\hline hsa-miR-144-5p & $0.51 \pm 0.21$ & $6.34 \pm 5.60$ & 10.18 & 0.0009 & 0.008 \\
\hline hsa-miR-186-5p & $3.41 \pm 1.27$ & $28.61 \pm 25.19$ & 8.18 & 0.0010 & 0.008 \\
\hline hsa-miR-142-3p & $0.12 \pm 0.11$ & $3.32 \pm 2.89$ & 19.50 & 0.0018 & 0.013 \\
\hline hsa-miR-425-3p & $0.14 \pm 0.12$ & $2.63 \pm 1.49$ & 15.21 & 0.0019 & 0.013 \\
\hline hsa-miR-22-3p & $41.30 \pm 3.23$ & $107.65 \pm 32.61$ & 2.61 & 0.0025 & 0.015 \\
\hline hsa-miR-183-5p & $0.52 \pm 0.26$ & $6.50 \pm 6.09$ & 10.71 & 0.0028 & 0.016 \\
\hline hsa-miR-363-3p & $6.27 \pm 1.47$ & $33.85 \pm 25.38$ & 5.31 & 0.0031 & 0.017 \\
\hline hsa-miR-16-5p & $5.80 \pm 1.19$ & $33.95 \pm 29.19$ & 5.72 & 0.0034 & 0.018 \\
\hline hsa-miR-629-5p & $2.05 \pm 0.75$ & $15.36 \pm 8.53$ & 7.08 & 0.0037 & 0.018 \\
\hline hsa-miR-23a-3p & $1.64 \pm 1.00$ & $17.76 \pm 3.39$ & 10.34 & 0.0050 & 0.022 \\
\hline hsa-miR-26b-5p & $6.66 \pm 1.50$ & $30.60 \pm 21.11$ & 4.42 & 0.0059 & 0.025 \\
\hline hsa-miR-106b-3p & $6.46 \pm 1.44$ & $31.58 \pm 26.15$ & 4.82 & 0.0079 & 0.032 \\
\hline hsa-miR-122-5p & $509.71 \pm 211.92$ & $14.04 \pm 14.04$ & 0.03 & 0.0081 & 0.032 \\
\hline hsa-miR-15b-5p & $1.26 \pm 0.42$ & $8.18 \pm 4.71$ & 6.02 & 0.0094 & 0.036 \\
\hline
\end{tabular}

${ }^{a}$ miRNAs are expressed as reads per million (rpm). miRNAs with less than $3 \mathrm{rpm}$ in more than $50 \%$ of the samples were removed from analysis

${ }^{\mathrm{b}}$ Fold change in tumor compared to healthy tissue

${ }^{c}$ False discovery rate. Only miRNAs with FDR lower than 0.05 were considered as significantly regulated 
Fig. 2 Venn diagram of miRNA expression among groups

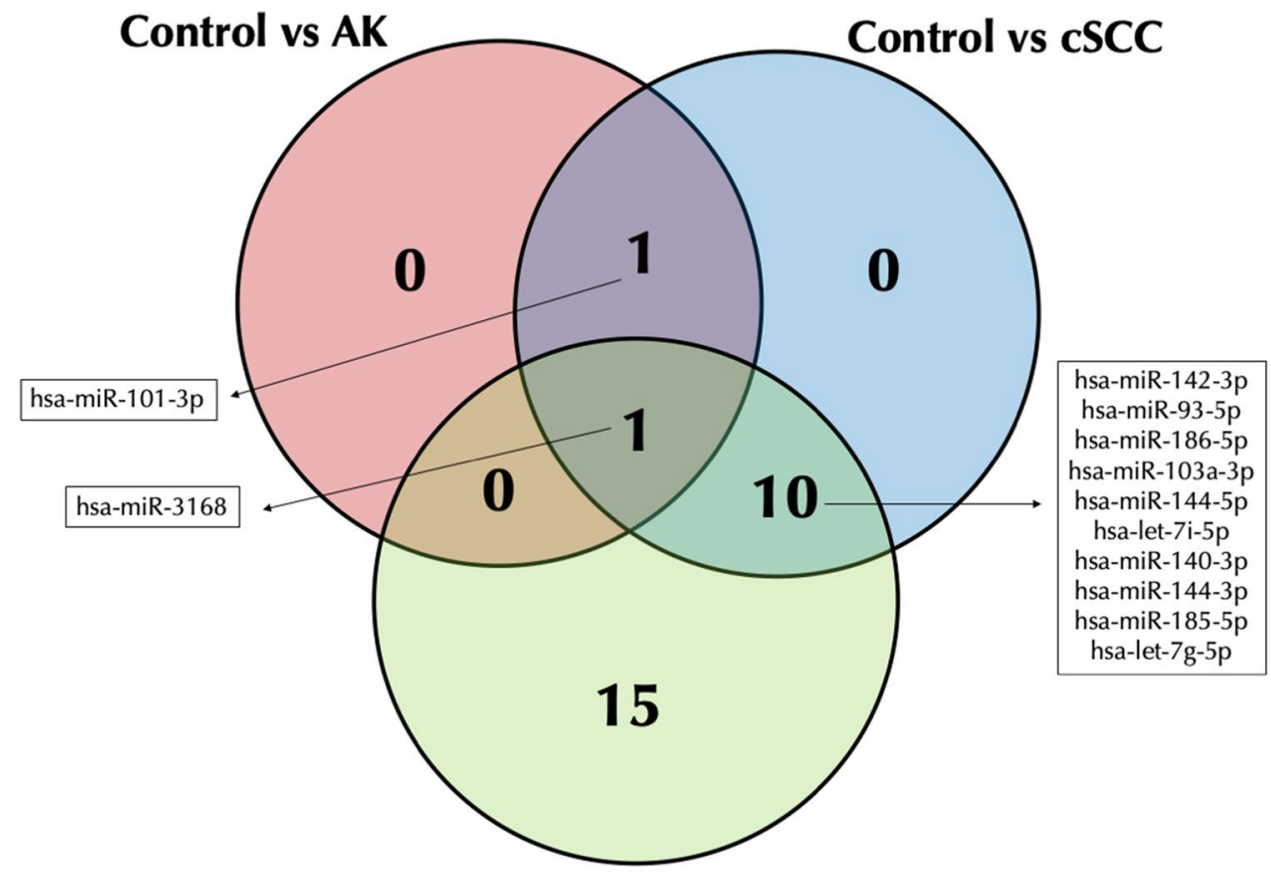

AK vs cSCC
Table 2 Pathways of target genes from miRNAs differentially expressed between control and AK tissue

\begin{tabular}{llcl}
\hline KEGG pathway & $P$ value & Genes & miRNAs \\
\hline Drug metabolism-cytochrome P450 & $1.11 \mathrm{E}-16$ & 1 & 1 \\
Morphine addiction & 0.002 & 11 & 2 \\
Signaling pathways regulating pluripotency of stem cells & 0.003 & 6 & 1 \\
TGF-beta signaling pathway & 0.004 & 9 & 1 \\
Endocrine and other factor-regulated calcium reabsorption & 0.013 & 1 & 1 \\
Mucin type O-glycan biosynthesis & 0.019 & 1 & 1 \\
Axon guidance & 0.047 & 15 & 1 \\
Dopaminergic synapse & 0.049 & 17 & 1 \\
cAMP signaling pathway & 0.050 & 24 & 1 \\
\hline
\end{tabular}

$[44,45]$. More functional studies are needed to better understand the role of miR-101-3p in AK and cSCC.

It surprised us the pattern of regulation for miR-3168. It was up-regulated in early stage AK lesions followed by a strong down-regulation in cSCC samples. Previous work in lung cancer has shown that miR-3168 is target of RNA editing, a common phenomenon that can contribute to development of diseases [46]. The authors observed a decrease in gene editing in early stage tumors followed by increased editing in late stage tumors [46]. Further functional studies are needed in skin cancer samples to confirm how this phenomenon can contribute to the changes in expression levels observed in serum.

We observed that the pathway 'drug metabolism'cytochrome P450 was the most enriched pathway in AK patients. The cytochrome $\mathrm{P} 450$ is a superfamily of enzymes known as detoxicant enzymes, catalyze the metabolism of several molecules, from lipids and steroidal hormones to xenobiotics [47]. As these enzymes have a role in the metabolism of environmental pollutants, they are involved in the pathogenesis of skin cancer. Ultraviolet-B induction of CYP enzymes in the skin could increase activation of environmental pollutants increasing susceptibility to skin cancers or allergic and irritant contact dermatitis [48]. CYP 450 enzymes are also involved in breast and prostate cancer due its ability to also metabolize steroid hormones [49]. Therefore, suggesting that miRNAs dysregulated in AK patients can contribute to CYP 450 mediated susceptibility to UV damage. 


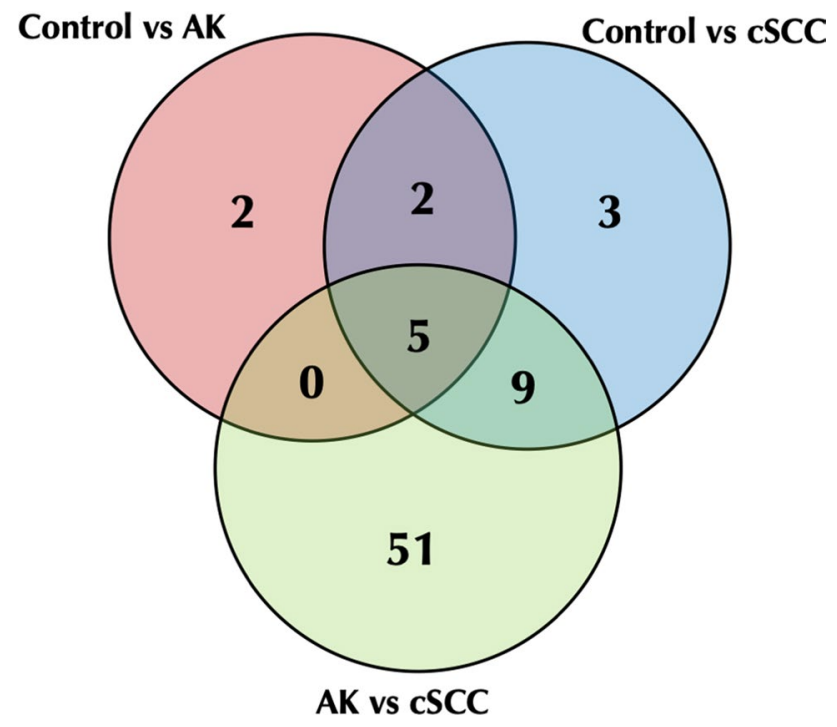

Fig. 3 Venn diagram of regulated KEGG pathways among groups

Importantly, based on our published data of circulating miRNAs in head and neck cancer, which allowed us to use differential expression of circulating miRNAs for successful separation of healthy from cancer patients, finding specific miRNAs correlating with different tumor stages, progression, and more importantly patients survival $[13,14,18$, 50], we strongly believe that presented in this study novel findings of differentially expressed circulating miRNAs in patients diagnosed with AK will allow as to use blood circulating miRNAs as non-invasive and easily accessible source of potential biomarkers of AK. More importantly, better understanding of the role of these miRNAs in AK will allow the use of blood circulating miRNAs for early screening for patients with high risk for $\mathrm{AK}$ and predicting potential progression towards $\mathrm{cSCC}$ in either healthy or already diagnosed patients while using less than $1 \mathrm{ml}$ of blood.

However, we are aware that there are several limitations of the study. The main one is the small study sample and we believe that the presented herein results present strong base for the introduction for further analysis using larger groups and development of more mechanistic studies evaluating the role of circulating miRNAs in AK and cSCC. Additionally, our work is based on analysis of Fitzpatrick II skin types and the skin limited to head location only, and as limiting the selection to one skin type and location represent more homogenous cohort, the inclusion of other skin types and localization would be valuable.

\section{Conclusion}

In sum, we detected a set of 2 miRNAs regulated in AK patients and 12 in cSCC patients. Some of these miRNAs were previously observed as important in AK, cSCC, and other types of skin cancer. Therefore, these miRNAs can be a tool for non-invasive diagnosis of AK and cSCC.
Table 3 Pathways of target genes from miRNAs differentially expressed between control and SSCC tissue

\begin{tabular}{llll}
\hline KEGG pathway & $P$ value & Genes & miRNAs \\
\hline Signaling pathways regulating pluripotency of stem cells & $1.14 \mathrm{E}-09$ & 55 & 5 \\
Proteoglycans in cancer & $2.39 \mathrm{E}-06$ & 72 & 4 \\
Axon guidance & $1.89 \mathrm{E}-04$ & 45 & 4 \\
Gap junction & 0.002 & 23 & 4 \\
Mucin type O-glycan biosynthesis & $6.29 \mathrm{E}-07$ & 6 & 4 \\
cAMP signaling pathway & 0.049 & 58 & 3 \\
Dopaminergic synapse & 0.008 & 46 & 3 \\
Adrenergic signaling in cardiomyocytes & 0.033 & 42 & 3 \\
Glutamatergic synapse & 0.022 & 33 & 2 \\
ErbB signaling pathway & 0.028 & 29 & 2 \\
Amphetamine addiction & $3.30 \mathrm{E}-04$ & 27 & 2 \\
TGF-beta signaling pathway & 0.010 & 24 & 2 \\
Transcriptional misregulation in cancer & 0.047 & 20 & 2 \\
ECM-receptor interaction & $1.11 \mathrm{E}-16$ & 8 & 2 \\
Glycosaminoglycan biosynthesis-chondroitin/dermatan sulfate & 0.013 & 4 & 2 \\
Glioma & 0.028 & 17 & 1 \\
Fatty acid metabolism & $4.86 \mathrm{E}-05$ & 3 & 1 \\
Fatty acid biosynthesis & $1.78 \mathrm{E}-15$ & 1 & 1 \\
Drug metabolism—cytochrome P450 & $3.33 \mathrm{E}-08$ & 1 & 1 \\
\hline
\end{tabular}


Table 4 Pathways of target genes from miRNAs differentially expressed between AK and SSCC tissue

\begin{tabular}{|c|c|c|c|}
\hline KEGG pathway & $P$ value & Genes & miRNAs \\
\hline Pathways in cancer & $2.06 \mathrm{E}-05$ & 188 & 24 \\
\hline PI3K-Akt signaling pathway & 0.001 & 155 & 24 \\
\hline Regulation of actin cytoskeleton & 0.001 & 103 & 23 \\
\hline Focal adhesion & 0.003 & 99 & 23 \\
\hline Signaling pathways regulating pluripotency of stem cells & $1.04 \mathrm{E}-05$ & 75 & 23 \\
\hline FoxO signaling pathway & $2.84 \mathrm{E}-04$ & 71 & 23 \\
\hline AMPK signaling pathway & $3.57 \mathrm{E}-04$ & 68 & 23 \\
\hline Dopaminergic synapse & 0.008 & 67 & 23 \\
\hline Tight junction & 0.004 & 65 & 23 \\
\hline ErbB signaling pathway & $3.57 \mathrm{E}-04$ & 51 & 23 \\
\hline MAPK signaling pathway & 0.003 & 119 & 22 \\
\hline Proteoglycans in cancer & $3.95 \mathrm{E}-12$ & 117 & 22 \\
\hline Ras signaling pathway & 0.004 & 101 & 22 \\
\hline Rap1 signaling pathway & 0.011 & 95 & 22 \\
\hline cAMP signaling pathway & 0.007 & 94 & 22 \\
\hline cGMP-PKG signaling pathway & 0.005 & 80 & 22 \\
\hline Adrenergic signaling in cardiomyocytes & $1.12 \mathrm{E}-05$ & 74 & 22 \\
\hline Insulin signaling pathway & 0.038 & 65 & 22 \\
\hline Neurotrophin signaling pathway & 0.003 & 63 & 22 \\
\hline Platelet activation & 0.005 & 63 & 22 \\
\hline Small cell lung cancer & 0.011 & 44 & 22 \\
\hline Estrogen signaling pathway & 0.044 & 43 & 22 \\
\hline mTOR signaling pathway & $3.49 \mathrm{E}-05$ & 40 & 22 \\
\hline Viral carcinogenesis & 0.003 & 74 & 21 \\
\hline Axon guidance & $5.18 \mathrm{E}-06$ & 69 & 21 \\
\hline Thyroid hormone signaling pathway & $5.18 \mathrm{E}-06$ & 66 & 21 \\
\hline Glutamatergic synapse & $6.88 \mathrm{E}-05$ & 61 & 21 \\
\hline Choline metabolism in cancer & 0.023 & 51 & 21 \\
\hline T-cell receptor signaling pathway & 0.038 & 51 & 21 \\
\hline Prostate cancer & 0.004 & 47 & 21 \\
\hline Melanoma & 0.003 & 39 & 21 \\
\hline Renal cell carcinoma & 0.006 & 38 & 21 \\
\hline Prolactin signaling pathway & 0.002 & 37 & 21 \\
\hline Glioma & $1.10 \mathrm{E}-04$ & 36 & 21 \\
\hline Pancreatic cancer & 0.002 & 36 & 21 \\
\hline Non-small cell lung cancer & 0.008 & 30 & 21 \\
\hline Oxytocin signaling pathway & $1.05 \mathrm{E}-04$ & 84 & 20 \\
\hline Hippo signaling pathway & $1.51 \mathrm{E}-05$ & 76 & 20 \\
\hline Wnt signaling pathway & $3.87 \mathrm{E}-04$ & 72 & 20 \\
\hline Sphingolipid signaling pathway & 0.001 & 62 & 20 \\
\hline Long-term potentiation & $3.57 \mathrm{E}-04$ & 41 & 20 \\
\hline Chronic myeloid leukemia & 0.013 & 37 & 20 \\
\hline Bacterial invasion of epithelial cells & 0.038 & 36 & 20 \\
\hline Cholinergic synapse & 0.030 & 54 & 19 \\
\hline Amoebiasis & 0.046 & 46 & 19 \\
\hline TGF-beta signaling pathway & $3.49 \mathrm{E}-05$ & 45 & 19 \\
\hline Insulin secretion & 0.044 & 41 & 19 \\
\hline Phosphatidylinositol signaling system & 0.005 & 40 & 19 \\
\hline p53 signaling pathway & 0.007 & 39 & 19 \\
\hline ECM-receptor interaction & $1.36 \mathrm{E}-04$ & 36 & 19 \\
\hline Long-term depression & 0.001 & 35 & 19 \\
\hline
\end{tabular}


Table 4 (continued)

\begin{tabular}{llll}
\hline KEGG pathway & $P$ value & Genes & miRNAs \\
\hline Dorso-ventral axis formation & 0.048 & 16 & 19 \\
Oocyte meiosis & 0.002 & 60 & 18 \\
Inflammatory mediator regulation of TRP channels & 0.034 & 47 & 18 \\
mRNA surveillance pathway & 0.019 & 46 & 18 \\
Gap junction & 0.001 & 44 & 18 \\
Amphetamine addiction & 0.010 & 33 & 18 \\
Colorectal cancer & 0.034 & 32 & 18 \\
Gastric acid secretion & 0.003 & 41 & 17 \\
Melanogenesis & 0.013 & 50 & 16 \\
Hedgehog signaling pathway & 0.010 & 29 & 16 \\
Type II diabetes mellitus & 0.021 & 26 & 16 \\
Circadian rhythm & 0.034 & 20 & 16 \\
Glycosaminoglycan biosynthesis-heparan sulfate/heparin & 0.014 & 12 & 12 \\
Fatty acid biosynthesis & $3.57 \mathrm{E}-11$ & 7 & 11 \\
\hline
\end{tabular}

Open Access This article is licensed under a Creative Commons Attribution 4.0 International License, which permits use, sharing, adaptation, distribution and reproduction in any medium or format, as long as you give appropriate credit to the original author(s) and the source, provide a link to the Creative Commons licence, and indicate if changes were made. The images or other third party material in this article are included in the article's Creative Commons licence, unless indicated otherwise in a credit line to the material. If material is not included in the article's Creative Commons licence and your intended use is not permitted by statutory regulation or exceeds the permitted use, you will need to obtain permission directly from the copyright holder. To view a copy of this licence, visit http://creativecommons.org/licenses/by/4.0/.

\section{References}

1. de Oliveira ECV, da Motta VRV, Pantoja PC, Ilha CSO, Magalhaes RF, Galadari H, Leonardi GR (2019) Actinic keratosisreview for clinical practice. Int J Dermatol 58:400-407

2. Fernandez Figueras MT (2017) From actinic keratosis to squamous cell carcinoma: pathophysiology revisited. J EurAcadDermatolVenereol 31(Suppl 2):5-7

3. Ratushny V, Gober MD, Hick R, Ridky TW, Seykora JT (2012) From keratinocyte to cancer: the pathogenesis and modeling of cutaneous squamous cell carcinoma. J ClinInvestig 122:464-472

4. Siegel JA, Korgavkar K, Weinstock MA (2017) Current perspective on actinic keratosis: a review. Br J Dermatol 177:350-358

5. Apalla Z, Lallas A, Sotiriou E, Lazaridou E, Ioannides D (2017) Epidemiological trends in skin cancer. DermatolPract Concept $7: 1-6$

6. Gurudutt VV, Genden EM (2011) Cutaneous squamous cell carcinoma of the head and neck. J Skin Cancer 2011:502723

7. Fernandez-Figueras MT, Carrato C, Saenz X, Puig L, Musulen E, Ferrandiz C, Ariza A (2015) Actinic keratosis with atypical basal cells (AK I) is the most common lesion associated with invasive squamous cell carcinoma of the skin. J EurAcadDermatolVenereol 29:991-997

8. Zhang L, Qin H, Wu Z, Chen W, Zhang G (2018) Pathogenic genes related to the progression of actinic keratoses to cutaneous squamous cell carcinoma. Int J Dermatol 57:1208-1217
9. Bartel DP (2004) MicroRNAs: genomics, biogenesis, mechanism, and function. Cell 116:281-297

10. Calin GA, Croce CM (2006) MicroRNA-cancer connection: the beginning of a new tale. Cancer Res 66:7390-7394

11. Volinia S, Calin GA, Liu CG, Ambs S, Cimmino A, Petrocca F, Visone R, Iorio M, Roldo C, Ferracin M, Prueitt RL, Yanaihara N, Lanza G, Scarpa A, Vecchione A, Negrini M, Harris CC, Croce CM (2006) A microRNA expression signature of human solid tumors defines cancer gene targets. ProcNatlAcadSci U S A 103:2257-2261

12. Gmerek L, Martyniak K, Horbacka K, Krokowicz P, Scierski W, Golusinski P, Golusinski W, Schneider A, Masternak MM (2019) MicroRNA regulation in colorectal cancer tissue and serum. PLoS ONE 14:e0222013

13. Schneider A, Victoria B, Lopez YN, Suchorska W, Barczak W, Sobecka A, Golusinski W, Masternak MM, Golusinski P (2018) Tissue and serum microRNA profile of oral squamous cell carcinoma patients. Sci Rep 8:675

14. Allen B, Schneider A, Victoria B, Nunez Lopez YO, Muller M, Szewczyk M, Pazdrowski J, Majchrzak E, Barczak W, Golusinski W, Golusinski P, Masternak MM (2018) Blood serum from head and neck squamous cell carcinoma patients induces altered microRNA and target gene expression profile in treated cells. Front Oncol 8:217

15. Garcia-Sancha N, Corchado-Cobos R, Perez-Losada J, Canueto J (2019) MicroRNA dysregulation in cutaneous squamous cell carcinoma. Int J MolSci 20:2181

16. Mizrahi A, Barzilai A, Gur-Wahnon D, Ben-Dov IZ, Glassberg S, Meningher T, Elharar E, Masalha M, Jacob-Hirsch J, TabibianKeissar H, Barshack I, Roszik J, Leibowitz-Amit R, Sidi Y, Avni D (2018) Alterations of microRNAs throughout the malignant evolution of cutaneous squamous cell carcinoma: the role of miR-497 in epithelial to mesenchymal transition of keratinocytes. Oncogene 37:218-230

17. Cortez MA, Bueso-Ramos C, Ferdin J, Lopez-Berestein G, Sood AK, Calin GA (2011) MicroRNAs in body fluids-the mix of hormones and biomarkers. Nat Rev ClinOncol 8:467-477

18. Nunez Lopez YO, Victoria B, Golusinski P, Golusinski W, Masternak MM (2018) Characteristic miRNA expression signature and random forest survival analysis identify potential cancerdriving miRNAs in a broad range of head and neck squamous cell carcinoma subtypes. Rep PractOncolRadiother 23:6-20 
19. Kolenda T, Guglas K, Rys M, Bogaczynska M, Teresiak A, Blizniak R, Lasinska I, Mackiewicz J, Lamperska KM (2017) Biological role of long non-coding RNA in head and neck cancers. Rep PractOncolRadiother 22:378-388

20. Chen X, Liang H, Zhang J, Zen K, Zhang CY (2012) Secreted microRNAs: a new form of intercellular communication. Trends Cell Biol 22:125-132

21. Vychytilova-Faltejskova P, Radova L, Sachlova M, Kosarova Z, Slaba K, Fabian P, Grolich T, Prochazka V, Kala Z, Svoboda M, Kiss I, Vyzula R, Slaby O (2016) Serum-based microRNA signatures in early diagnosis and prognosis prediction of colon cancer. Carcinogenesis 37:941-950

22. Zheng H, Zhang L, Zhao Y, Yang D, Song F, Wen Y, Hao Q, Hu Z, Zhang W, Chen K (2013) Plasma miRNAs as diagnostic and prognostic biomarkers for ovarian cancer. PLoS ONE 8:e77853

23 Mumford SL, Towler BP, Pashler AL, Gilleard O, Martin Y, Newbury SF (2018) Circulating MicroRNA Biomarkers in Melanoma: Tools and Challenges in Personalised Medicine. Biomolecules $8: 21$

24. Werner RN, Stockfleth E, Connolly SM, Correia O, Erdmann R, Foley P, Gupta AK, Jacobs A, Kerl H, Lim HW, Martin G, Paquet M, Pariser DM, Rosumeck S, Rowert-Huber HJ, Sahota A, Sangueza OP, Shumack S, Sporbeck B, Swanson NA, Torezan L, Nast A, International League of Dermatological, S., and European Dermatology, F. (2015) Evidence- and consensus-based (S3) Guidelines for the Treatment of Actinic Keratosis - International League of Dermatological Societies in cooperation with the European Dermatology Forum - Short version. J EurAcadDermatolVenereol 29:2069-2079

25. Matkovich SJ, Hu Y, Dorn GWII (2013) Regulation of cardiac microRNAs by cardiac microRNAs. Circ Res 113:62-71

26. Rueda A, Barturen G, Lebron R, Gomez-Martin C, Alganza A, Oliver JL, Hackenberg M (2015) sRNAtoolbox: an integrated collection of small RNA research tools. Nucleic Acids Res 43:W467-473

27. Robinson MD, McCarthy DJ, Smyth GK (2010) edgeR: a Bioconductor package for differential expression analysis of digital gene expression data. Bioinformatics 26:139-140

28. Vlachos IS, Zagganas K, Paraskevopoulou MD, Georgakilas G, Karagkouni D, Vergoulis T, Dalamagas T, Hatzigeorgiou AG (2015) DIANA-miRPath v3.0: deciphering microRNA function with experimental support. Nucleic Acids Res 43:W460-466

29. Kanehisa M, Goto S (2000) KEGG: kyotoencyclopedia of genes and genomes. Nucleic Acids Res 28:27-30

30. Kanehisa M, Sato Y, Kawashima M, Furumichi M, Tanabe M (2016) KEGG as a reference resource for gene and protein annotation. Nucleic Acids Res 44:D457-462

31. Neagu M, Constantin C, Cretoiu SM, Zurac S (2020) miRNAs in the diagnosis and prognosis of skin cancer. Front Cell Dev Biol $8: 71$

32. Bai X, Zhou Y, Chen P, Yang M, Xu J (2018) MicroRNA142-5p induces cancer stem cell-like properties of cutaneous squamous cell carcinoma via inhibiting PTEN. J Cell Biochem 119:2179-2188

33. Liu C, Yu Z, Huang S, Zhao Q, Sun Z, Fletcher C, Jiang Y, Zhang D (2019) Combined identification of three miRNAs in serum as effective diagnostic biomarkers for HNSCC. EBioMedicine 50:135-143

34. Kaduthanam S, Gade S, Meister M, Brase JC, Johannes M, Dienemann H, Warth A, Schnabel PA, Herth FJ, Sultmann H, Muley T, Kuner R (2013) Serum miR-142-3p is associated with early relapse in operable lung adenocarcinoma patients. Lung Cancer $80: 223-227$

35. Ming M, He YY (2009) PTEN: new insights into its regulation and function in skin cancer. J Invest Dermatol 129:2109-2112
36. Backman SA, Ghazarian D, So K, Sanchez O, Wagner KU, Hennighausen L, Suzuki A, Tsao MS, Chapman WB, Stambolic V, Mak TW (2004) Early onset of neoplasia in the prostate and skin of mice with tissue-specific deletion of Pten. ProcNatlAcadSci USA 101:1725-1730

37. Koury J, Zhong L, Hao J (2017) Targetingsignaling pathways in cancer stem cells for cancer treatment. Stem Cells Int 2017:2925869

38. Malanchi I, Peinado H, Kassen D, Hussenet T, Metzger D, Chambon P, Huber M, Hohl D, Cano A, Birchmeier W, Huelsken J (2008) Cutaneous cancer stem cell maintenance is dependent on beta-catenin signalling. Nature 452:650-653

39. Buraschi S, Pal N, Tyler-Rubinstein N, Owens RT, Neill T, Iozzo RV (2010) Decorin antagonizes Met receptor activity and down-regulates \{beta\}-catenin and Myc levels. J BiolChem 285:42075-42085

40. Fogli S, Polini B, Carpi S, Pardini B, Naccarati A, Dubbini N, Lanza M, Breschi MC, Romanini A, Nieri P (2017) Identification of plasma microRNAs as new potential biomarkers with high diagnostic power in human cutaneous melanoma. Tumour Biol 39:1010428317701646

41. Satzger I, Mattern A, Kuettler U, Weinspach D, Voelker B, Kapp A, Gutzmer R (2010) MicroRNA-15b represents an independent prognostic parameter and is correlated with tumor cell proliferation and apoptosis in malignant melanoma. Int $\mathrm{J}$ Cancer 126:2553-2562

42. Wang J, Zeng H, Li H, Chen T, Wang L, Zhang K, Chen J, Wang R, Li Q, Wang S (2017) MicroRNA-101 inhibits growth, proliferation and migration and induces apoptosis of breast cancer cells by targeting sex-determining region Y-Box 2. Cell PhysiolBiochem 43:717-732

43. Li CY, Xiong DD, Huang CQ, He RQ, Liang HW, Pan DH, Wang HL, Wang YW, Zhu HW, Chen G (2017) Clinical value of miR101-3p and biological analysis of its prospective targets in breast cancer: a study based on The Cancer Genome Atlas (TCGA) and Bioinformatics. Med SciMonit 23:1857-1871

44. Imamura T, Komatsu S, Ichikawa D, Miyamae M, Okajima W, Ohashi T, Kiuchi J, Nishibeppu K, Kosuga T, Konishi H, Shiozaki A, Okamoto K, Fujiwara H, Otsuji E (2017) Low plasma levels of miR-101 are associated with tumor progression in gastric cancer. Oncotarget 8:106538-106550

45. Yao ZS, Li C, Liang D, Jiang XB, Tang JJ, Ye LQ, Yuan K, Ren $\mathrm{H}$, Yang ZD, Jin DX, Zhang SC, Ding JY, Tang YC, Xu JX, Chen K, Xie WX, Guo DQ, Cui JC (2018) Diagnostic and prognostic implications of serum miR-101 in osteosarcoma. Cancer Biomark 22:127-133

46. Nigita G, Distefano R, Veneziano D, Romano G, Rahman M, Wang K, Pass H, Croce CM, Acunzo M, Nana-Sinkam P (2018) Tissue and exosomalmiRNA editing in non-small cell lung cancer. Sci Rep 8:10222

47. McDonnell AM, Dang CH (2013) Basic review of the cytochrome p450 system. J AdvPractOncol 4:263-268

48. Katiyar SK, Matsui MS, Mukhtar H (2000) Ultraviolet-B exposure of human skin induces cytochromes P450 1A1 and 1B1. J Invest Dermatol 114:328-333

49. Elfaki I, Mir R, Almutairi FM, Duhier FMA (2018) Cytochrome P450: polymorphisms and roles in cancer, diabetes and atherosclerosis. Asian Pac J Cancer Prev 19:2057-2070

50. Victoria Martinez B, Dhahbi JM, Nunez Lopez YO, Lamperska K, Golusinski P, Luczewski L, Kolenda T, Atamna H, Spindler SR, Golusinski W, Masternak MM (2015) Circulating small noncoding RNA signature in head and neck squamous cell carcinoma. Oncotarget 6:19246-19263

Publisher's Note Springer Nature remains neutral with regard to jurisdictional claims in published maps and institutional affiliations. 